\title{
La terapia de reemplazo hormonal disminuiría la sensibilidad de la mamografía en el rastreo de cáncer de mama
}

Hormone replacement therapy and accuracy of mammographic screening;

Kavannagh AM, Mitchell H, Giles GG. Lancet 2000; 355:270-274.

Objetivo
Evaluar en que medida la terapia de reemplazo hormonal (TRH) afecta
la exactitud de la mamografía para el rastreo de cáncer de mama (CM).

Diseño

Estudio de cohorte prospectivo*, con dos años de seguimiento (19941996)

Lugar

Realizado en el estado de Victoria, Australia

\section{Pacientes}

Participaron 103770 mujeres (93830 mujeres tenían entre 40 y 69 años de edad y 9940 más de 70 años) que concurrieron a realizar su primer mamografía de control en 1994. Se excluyeron aquellas con historia personal de CM, secreción por pezón o nódulo mamario. El grupo en el que se hizo hincapié fueron las mujeres entre 50 y 69 años de edad que nunca habían realizado su control mamográfico, a las que se envió una invitación. Todas completaron un cuestionario que registraba los datos personales y el uso de TRH.

\section{Descripción del test y del test de referencia}

A todas las participantes se les realizó dos vistas mamográficas, que fueron evaluadas por dos radiólogos de manera independiente. En el caso que no hubiere acuerdo entre los informes, se realizaba un consenso entre ambos o bien, tomaba la decisión un tercer radiólogo. La paciente que presentaba un estudio anormal era referida para realizar un examen clínico, otro estudio por imágenes, punción o biopsia mamaria.

\section{Medición de resultados}

Las pacientes fueron clasificadas en cuatro categorías, según el resultado fuera un verdadero negativo (VN), falso positivo (FP), verdadero positivo (VP) y falso negativo (FN).

Se consideró un resultado VN cuando la paciente no desarrolló cáncer en el intervalo inter rastreo; $\mathrm{FP}$ al caso derivado por el screening que no fueran diagnosticados cáncer; VP aquella que resultó cáncer invasivo luego del rastreo y FN la que desarrolló cáncer invasivo en el intervalo recomendado entre mamografías de rastreo (24 meses). Los casos de cáncer eran identificados por el registro de Victoria entre 1994 y 1996.

\section{Resultados principales}

El 27\% de las participantes utilizaba TRH. En este grupo, la sensibilidad de la mamografía fue un $12.5 \%$ menor (IC 95\% 5-20); sensibilidad en usadoras $64.8 \%$ (IC 95\% 57.9-71.8) vs. $77.3 \%$ (73.8-80.9) en las no usadoras de hormonas. Para el primer año de rastreo la sensibilidad fue del $83.7 \%$ (78-90) vs. $91.4 \%$ (89-94) respectivamente. También se observó una tendencia a la menor detección de CM pequeños en las usadoras de TRH. La especificidad fue similar en ambos grupos.

\begin{tabular}{lll}
\hline Resultado & Sin TRH & Con TRH \\
VN & 71215 & 26600 \\
\hline FP & 3689 & 1550 \\
\hline VP & 413 & 118 \\
\hline FN & 121 & 64 \\
\hline CM detectados en el rastreo & 147 & 39 \\
\hline Especificidad & $95.1 \%(94.9-95.2)$ & $94.5 \%(94.2-94.8)$ \\
\hline Sensibilidad & $77.3 \%(73.8-80.9)$ & $64.8 \%(57.9-71.8)$ \\
\hline Cáncer pequeño detectado & & \\
C/ 10000 mujeres & $19.5(16.5-22.9)$ & $13.8(9.8-18.1)$ \\
\hline
\end{tabular}

\section{Conclusiones}

El uso de TRH se asoció a una menor sensibilidad del rastreo mamográfico. Esta menor sensibilidad podría limitar el impacto benéfico sobre la mortalidad en los lugares en que se utiliza el rastreo poblacional de rutina.

\section{COMENTARIO}

A partir de la introducción de programas de rastreo de CM, con mamografía y examen físico, se ha demostrado que el riesgo de morir por el mismo disminuye entre un 20 y 39\% ${ }^{1}$. La utilidad de la mamografía para su rastreo ha sido confirmada en diferentes ensayos. En un estudio se evaluaron 28271 mujeres que realizaban mamografía de screening por primera vez. Se observó que la sensibilidad de la misma era mayor en el grupo de mujeres de 50 o más años que en las menores de 50. También se observó que para ambos grupos etarios la sensibilidad disminuía con el tiempo. La densidad mamaria no afectó la sensibilidad de la mamografía; y la especificidad fue similar en ambos grupos etarios. ${ }^{2}$

Uno de los interrogantes que se plantea en el rastreo de CM, es como afecta la TRH el rendimiento del test. Es oportuno mencionar que este tipo de trabajo se enfrenta a una dificultad: el "test de referencia o gold standard", ya que no es factible obtener un punto duro como por ejemplo la histología de todas las pacientes. En diferentes estudios se ha calculado la tasa de resultados falsos positivos y falsos negativos de manera diferente, por lo que los resultados no son consistentes. Sin embargo, en un estudio prospectivo (que usó las mismas definiciones que el artículo que se presenta para los resultados FP y FN) se *Ver glosario

\section{Dra. Vilda Discacciati}

Unidad de Medicina Familiar y Preventiva. Hospital Italiano de Buenos Aires. evaluó las características de la mamografía de rastreo en relación a la TRH, con 28 meses de seguimiento, observando que para las mujeres que estaban recibiendo TRH la sensibilidad fue del $96 \%$ (IC 95\% 81 $99.1 \%$ ), en las que habían recibido hormonas previamente de $92 \%$ (IC 95\% 61.5-99.8\%) y del $91 \%$ (94.8-95.5\%) en las que nunca habian recibido hormonas; la especificidad fue cercana al $95 \%$ en todos los grupos. ${ }^{3}$ Estos resultados no concuerdan con los obtenidos en el estudio que se presenta, lo que podría deberse a la diferencia en el número de pacientes (28 000 vs. 103770 ); por otro lado, a diferencia del trabajo citado, en este estudio no queda explicitado el tipo y el tiempo de la terapia hormonal.

En síntesis parecería que la especificidad de la mamografía, según los estudios publicados, no varía de manera clínicamente importante en relación a la utilización de TRH y tampoco con la edad, pero no queda del todo claro como se modifica su sensibilidad, más aún cuando en este trabajo consideran como resultados falsos negativos a los tumores de intervalo. Yendo al consultorio, se mantienen por ahora las recomendaciones de mamografía anual en aquellas mujeres que reciben TRH, a diferencia de las que no la reciben que pueden realizarla cada dos años.

\section{Referencias}

1. Karla Kerlikowse, Deborah Grady, Susan Rubin et al. Efficacy of screening mammography. A meta-analisis. JAMA 1995; 273: 149-54.

2. Karla Kerlikowske et al. Effect of age, breast density, and family history on the sensitivity of first screening mammography. JAMA 1996; 276 (33-38)

3. Erik Thurfiell, Lars Holmberg, Ingemar Persson. Screening mammography: Sensitivity and speceficity in relation to hormone replacement therapy. Radiology $1997 ; 203: 339-34.1$ 